\title{
Review
}

\section{Complex regional pain syndrome - diagnostic, mechanisms, CNS involvement and therapy}

\author{
G Wasner*,1, J Schattschneider ${ }^{1}$, A Binder ${ }^{1}$ and R Baron ${ }^{1}$ \\ ${ }^{1}$ Klinik für Neurologie, Universitätsklinikum Kiel, 24105 Kiel, Germany
}

\begin{abstract}
Complex regional pain syndromes (CRPS, formerly reflex sympathetic dystrophy and causalgia) are neuropathic pain conditions of one extremity developing inadequately after a trauma. The initiating trauma affects primarily the extremity, but can also be a central lesion (e.g., spinal cord injury, stroke). CRPS is clinically characterized by sensory, autonomic and motor disturbances. Pathophysiologically there is evidence for functional changes within the central nervous system and for involvement of peripheral inflammatory processes. The sympathetic nervous system plays a key role in maintaining pain and autonomic dysfunction in the affected extremity. After a primary central lesion, secondary peripheral changes in the paretic extremity are suggested to be important in initiating a CRPS. Though there is no diagnostic gold standard, careful clinical evaluation and additional test procedures should lead to an adequate diagnosis. An early diagnosis and an interdisciplinary approach are important for optimal and successful treatment.
\end{abstract}

Spinal Cord (2003) 41, 61-75. doi:10.1038/sj.sc.3101404

Keywords: complex regional pain syndrome; reflex sympathetic dystrophy; sympathetic; central nervous system; inflammation; treatment

\section{Introduction}

Complex regional pain syndromes (CRPS, formerly reflex sympathetic dystrophy and causalgia) are neuropathic pain disorders developing as a disproportionate consequence of painful trauma or a nerve lesion affecting the limbs, or a bone fracture, or as a consequence of a remote process like stroke, spinal cord injury and myocardial infarction. ${ }^{1}$ Clinical features that occur in a distal generalized distribution are spontaneous pain, allodynia, hyperalgesia, autonomic and motor dysfunction. In 1872 the American Civil War physician, Weir Mitchell, was the first who describe a pain syndrome, named causalgia, developing in the distal extremity following traumatic partial nerve injury. The affected extremity was characterized by sensory and trophic symptoms spreading beyond the innervation territory of the injured peripheral nerve. Early in the last century Paul Sudeck described similar symptoms in an extremity pain syndrome that developed after distal bone fractures without affecting any peripheral nerve. Based on the experience that patients with Sudeck's syndrome obtained dramatic pain relief by sympathetic block, the term reflex

*Correspondence: G Wasner, Klinik für Neurologie, ChristianAlbrechts-Universität Kiel, Niemannsweg 147, 24105 Kiel, Germany sympathetic dystropy was introduced by Evans in 1946 to accommodate the suggested pathophysiological role of the sympathetic nervous system. Following the growing evidence from recent years that sympathetically maintained pain (SMP) is still an important symptom, but not obligatorily necessary for the diagnosis of these disorders, a new terminology was introduced based entirely on elements of history, symptoms and findings on clinical examination, with no implied pathophysiological mechanism. ${ }^{2}$ According to the International Association for the Study of Pain (IASP) 'Classification of Chronic Pain', reflex sympathetic dystrophy and causalgia are now called complex regional pain syndromes (CRPS). In CRPS type I (reflex sympathetic dystrophy), minor injuries to a limb or lesions in remote body areas precede the onset of symptoms. CRPS type II (causalgia) develops after injury to a major peripheral nerve. ${ }^{3}$ Recent investigations of autonomic, motor and somatosensory abnormalities indicate that the whole picture of CRPS is considered to be a neurological disorder involving the central nervous system as well as a peripheral neurogenic inflammatory process. ${ }^{4}$ However, the general awareness of CRPS is still poor, because on average thirty months pass by until patients are admitted to a pain center for adequate therapy. ${ }^{5}$ 


\section{Clinical picture of complex regional pain syndromes}

\section{CRPS type I (reflex sympathetic dystrophy)}

Noxious events, including minor trauma (eg sprains, bruises, soft tissue trauma, frostbite or skin lesions), bone fracture or surgery of the affected extremity often determine the onset of CRPS I. Occasionally the disease develops after other medical events such as shoulder trauma, myocardial infarction or a lesion of the central nervous system. A peripheral nerve lesion is not detectable, ${ }^{6}$ although one histopathological study demonstrated damage of small afferent fibers in CRPS after leg amputation. ${ }^{7}$ The clinical picture of CRPS I is characterized by sensory, autonomic, trophic and motor abnormalities, as well as sometimes inflammatory symptoms (Figure 1). ${ }^{8-12}$

Sensory symptoms These include a burning spontaneous pain felt in the distal part of the affected extremity. ${ }^{13}$ Characteristically, the pain is disproportionate in intensity to the inciting event. The pain usually increases when the extremity is in a dependent position. Stimulus-evoked pains are a striking clinical feature; they include mechanical and thermal allodynia and/or hyperalgesia. These sensory abnormalities often appear early, are most pronounced distally, and have no consistent spatial relationship to individual nerve territories or to the site of the inciting lesion. ${ }^{14-16}$ Typically the pain can be elicited by movements and pressure at the joints, even if these are not directly affected by the inciting lesion. In addition, somatosensory deficits may be present. ${ }^{17,18}$

Autonomic abnormalities These include swelling and changes of sweating and skin blood flow (Figure 1). ${ }^{19-25}$ At normal room temperature the skin temperature of the limbs shows an inconstant side difference in about $30-80 \%$ of the patients, ie the affected extremity is

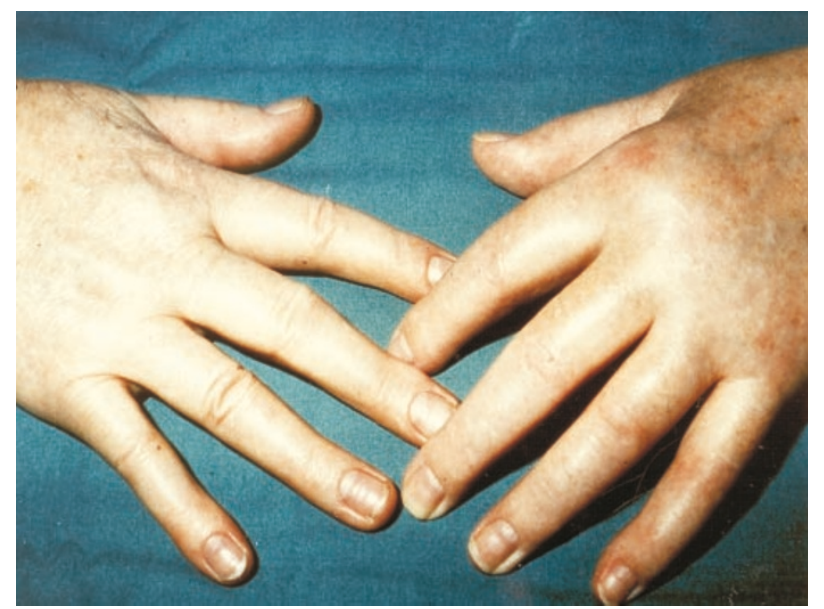

Figure 1 Patient with acute CRPS. The patient developed CRPS of the left hand after a radial fracture. Marked swelling two weeks after the initial trauma. Adapted from ${ }^{169}$, with permission either warmer or colder. In the acute stages of CRPS I the affected limb is more often warmer than the contralateral limb. It is likely that there is an inflammatory component of CRPS I in the acute phase that contributes to pain and skin warming. Sweating abnormalities are present in nearly all CRPS I patients. Either hypohidrosis or, more frequently, hyperhidrosis is present. ${ }^{19,23,26}$ The acute distal swelling of the affected limb depends very critically on aggravating stimuli. Since it often diminishes after sympathetic blocks, it is likely that it is maintained by sympathetic activity. ${ }^{11}$

Trophic changes Trophic changes such as abnormal nail growth, increased or decreased hair growth, fibrosis, thin glossy skin and osteoporosis may be present, particularly in chronic stages. Restrictions of passive movement are often present in long-standing cases and may be related to both functional motor disturbances and trophic changes of joints and tendons.

Motor symptoms Weakness of all muscles of the affected distal extremity are often present. ${ }^{27}$ Small accurate movements are characteristically impaired. ${ }^{11}$ Nerve conduction and electromyography studies are normal, except in patients in very chronic and advanced stages. Therefore, the peripheral motor neuron and the neuromuscular junction are unlikely to contribute to the motor dysfunction. About half of the patients have a postural or action tremor that represents an increased physiological tremor. ${ }^{28}$ In about $10 \%$ of cases dystonia of the affected hand or foot develops. ${ }^{29,30}$

An important feature of CRPS I is that the severity of symptoms is disproportionate to the severity of trauma, with a tendency to generalize in the affected distal limb but not to be confined to the innervation zone of an individual nerve. Thus, all symptoms of CRPS I may occur irrespective of the type of the preceding lesion. ${ }^{31}$ Furthermore, the site of the lesion at the limb does not determine the location of symptoms. ${ }^{32}$

\section{CRPS type II (Causalgia)}

CRPS II develops in the distal extremity following traumatic partial peripheral nerve lesion. In the earliest systematic description of causalgia, Weir Mitchell noted that in addition to spontaneous pain, patients reported exquisite hypersensitivity of the skin to light mechanical stimulation. ${ }^{33,34}$ Furthermore, movement, loud noises or strong emotions might trigger their pain. Distal extremity swelling, smoothness and mottling of the skin, and in some cases, acute arthritis was present. In most cases the limb was cold and sweaty. The sensory and trophic abnormalities spread beyond the innervation territory of the injured peripheral nerve and showed a distally generalized distribution. Since all symptoms show many similarities to those of CRPS I, this syndrome is now called CRPS II. 


\section{Post-traumatic neuralgia}

It is important to recognize that in many posttraumatic neuropathy patients the pain is located largely within the innervation territory of the injured nerve. ${ }^{35}$ Although these patients often describe their pain as burning, they exhibit a less complex clinical picture than patients with causalgia, and do not show marked swelling or a tendency for progressive spread of symptoms. The cardinal symptoms are spontaneous burning pain, hyperalgesia and mechanical and especially cold allodynia. These sensory symptoms are confined to the territory of the affected peripheral nerve although allodynia may extend beyond the border of nerve territories to a certain degree. Spontaneous and evoked pain are felt superficially and not deep inside the extremity, and the intensity of both is not dependent on the position of the extremity. Following the IASP classification it is possible to use the name 'neuralgia' for this type of neuropathic pain (pain within the innervation territory of a lesioned nerve, eg post-traumatic neuralgia). However, the definition of CRPS II includes the statement that symptoms may also be limited to the territory of a single peripheral nerve. ${ }^{3}$ Therefore, the term CRPS II provides space to include these localized post-traumatic neuropathies. An inherent weakness of this definition of CRPS II is that different syndromes with different underlying mechanisms are obviously included.

Despite the described symptoms one has to be aware of other clinical entities that demonstrate a similar clinical picture to CRPS, eg neuropathy. ${ }^{36,37}$

Recent validation of the current IASP definition for CRPS indicated that modifications of the diagnostic criteria have to be performed in the near future to improve specificity and sensitivity. ${ }^{38}$

\section{CRPS after stroke and spinal cord injury}

Stroke Interestingly, CRPS may also develop after central lesions. Gellman et al. reported that $12 \%$ of brain-injured patients complained about symptoms of reflex sympathetic dystrophy. ${ }^{39}$ The incidence for CRPS in the affected paretic upper extremity after stroke ranges between 1.5 and $61 \% .^{40-43}$ One reason for this large variation of data is probably that many symptoms of CRPS are also found in stroke patients. Motor abnormalities like paresis, somatotensory abnormalities and neglect, are typical features in stroke patients. Furthermore, skin temperature of the paretic extremity decreases in more than $50 \%$ of the patients after stroke. ${ }^{44,45}$ Disuse might be an important factor for these cold hands. ${ }^{46}$ The development of unilateral sweating abnormalities after stroke led to the hypothesis that autonomic disturbances in stroke and CRPS might share a common central pathophysiology. ${ }^{47}$ Pain is also a frequent symptom after a central lesion. Central pain, eg after thalamic lesions, has a burning characteristic and is often associated with allodynia. Furthermore, peripheral traumatic injury of the shoulder led to painful extremities after stroke, as demonstrated by shoulder joint capsules taken at autopsy. ${ }^{48}$ Important risk factors for development of such a peripheral shoulder-hand syndrome are subluxation, paresis of the shoulder girdle, moderate spasticity and visual deficits for the paretic extremity. The peripheral lesion might initiate a self-perpetuating vicious cycle of pain followed by the full picture of CRPS in some patients (Figure 2). ${ }^{48}$ Similarly, in brain-injured patients associated extremity injury appears to be at a significantly higher risk of developing CRPS. ${ }^{39}$

Spinal cord injury Although chronic pain is a frequent symptom in patients with spinal cord injury, the association with CRPS seems to be relatively rare with an estimated incidence of about $5-10 \% .^{49-52}$ In a retrospective study of 125 patients with reflex sympathetic dystrophy only two patients had previous neck injury. ${ }^{53}$ CRPS appears within a few months following injury, and most often affects unilaterally one upper extremity in tetraplegia patients, whereas bilateral involvement or CRPS at the lower extremity have rarely been reported. ${ }^{54-57}$ Similar to stroke, more patients seem to have some features of CRPS without developing the complete syndrome. ${ }^{58}$ An important predisposing factor is a medullary gunshot wound, although it only represents $10 \%$ of the etiology of spinal cord injury. ${ }^{54}$ The association of CRPS in tetraplegia with limb trauma and shoulder pain may

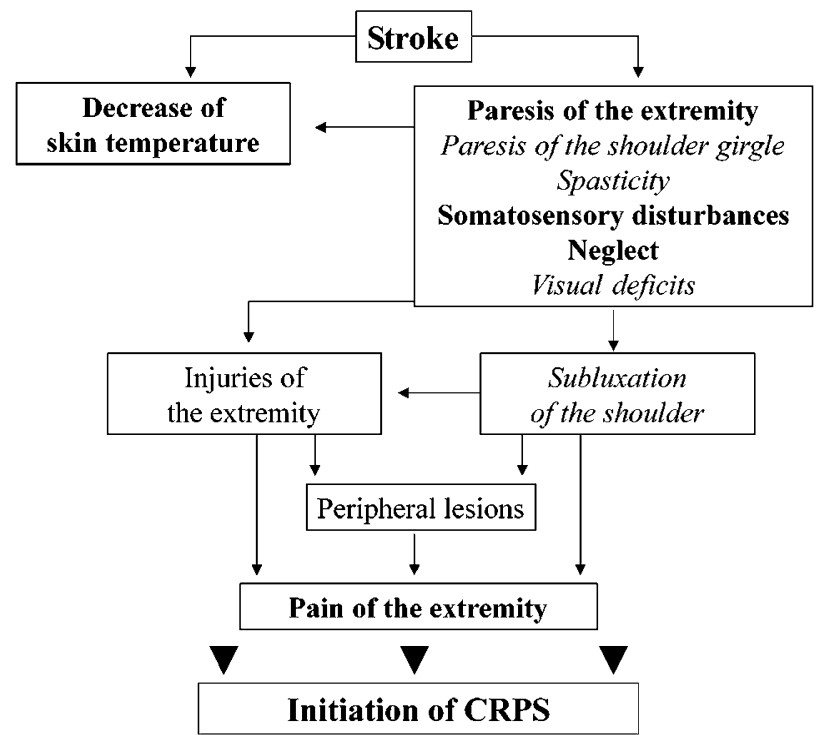

Figure 2 Hypothesis on the development of CRPS after stroke affecting the upper extremity. Stroke deficits due to the central infarction may lead to secondary peripheral lesions that might initiate a self-perpetuating vicious cycle of pain followed by the full picture of CRPS in a minority of patients. Many symptoms in a majority of stroke patients that are due to the central lesion are at least partially also found in CRPS (bold type). Risk factors for development of painful shoulder-hand syndrome are italicized 
indicate that peripheral mechanisms are involved in initiating CRPS, similar to that decribed in stroke. $^{48,50,54}$ CRPS may be one cause of contractures in patients with spinal cord injury. ${ }^{59}$

\section{CRPS and sympathetically maintained pain}

The former term 'reflex sympathetic dystrophy' for CRPS was based on the experience that sympatholytic procedures relieved pain in many patients. However, it became clear in recent years that pain depending on sympathetic activity is not necessary for the diagnosis of CRPS, because not all patients respond to sympatholytic procedures. Furthermore, it is not specific, because other neuropathic pain conditions might benefit from sympathetic blocks (Figure 3). Therefore, the term sympathetically maintained pain was re-defined: Neuropathic pain patients presenting with similar clinical signs and symptoms, can be divided into two groups by the negative or positive effect of selective sympathetic blockade or antagonism of alpha adrenoceptor mechanisms. ${ }^{60,61}$ The pain component that is relieved by specific sympatholytic procedures is considered 'sympathetically maintained pain' (SMP). Thus, SMP is now defined to be a symptom or the underlying mechanism in a subset of patients with neuropathic disorders and not a clinical entity. The positive effect of a sympathetic blockade is not essential for the diagnosis. On the other hand, the only possibility to differentiate between SMP and 'sympathetically independent pain' (SIP) is the efficacy of a correctly applied sympatholytic intervention. ${ }^{2}$

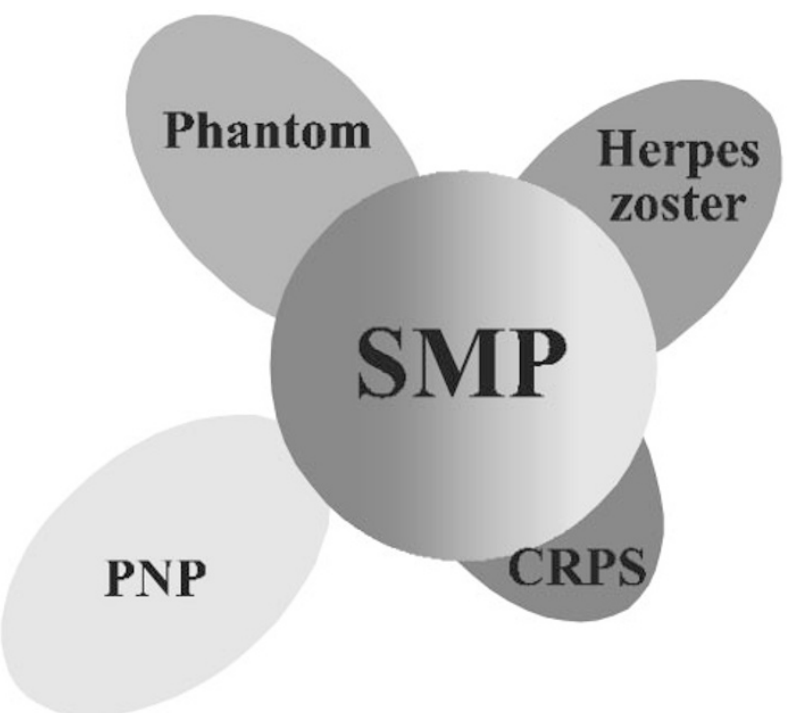

Figure 3 Neuropathic pain conditions with the facultative symptom of sympathetically maintained pain (SMP). CRPS patients have the highest incidence of an SMP followed by patients suffering from acute herpes zoster or postherpetic neuralgia, phantom limb pain and polyneuropathy (PNP)

\section{Pathophysiological mechanisms in CRPS}

Although the entire pathophysiology of CRPS is not resolved, evidence from human experimentation and animal studies illuminate many aspects of the underlying pathophysiological mechanisms.

\section{The sympathetic nervous system}

The clinical picture of autonomic dysfunction with changes in skin blood flow, temperature and sweating, as well as the symptom of sympathetically maintained pain, suggests that the sympathetic nervous system is involved in the pathophysiology of CRPS. Physiologically, sympathetic preganglionic neurons, which are involved in regulation of effector cells in somatic tissues, project to the paravertebral ganglia of the sympathetic trunk and synapse with postganglionic neurons that innervate the effector cells. These preganglionic sympathetic neurons are under central control, and the pattern of ongoing and reflex discharges is characteristic for each type of sympathetic pathway, eg skin vasoconstrictor, muscle vasoconstrictor and sudomotor neurons, and varies according to the innervated target cells. ${ }^{62,63}$ Under normal conditions sympathetic activity does not interact with the nociceptive neurons in the periphery. ${ }^{64,65}$

Autonomic disturbances A partial nerve lesion is the important preceding event in CRPS II. Therefore, it has generally been assumed that abnormalities in skin blood flow within the territory of the lesioned nerve are due to peripheral impairment of sympathetic function and sympathetic denervation. During the first weeks after transection of vasoconstrictor fibers, vasodilatation is present within the denervated area. Later the vasculature may develop increased sensitivity to circulating catecholamines, probably due to upregulation of adrenoceptors. ${ }^{66}$ Similar observations were recently described in the chronic nerve constriction injury model in rats. ${ }^{67,68}$ The skin on the lesioned side was abnormally warm for about the first post-operative week and then evolved to a chronically cold status. The late-stage cold skin was present despite a complete absence of fluorescence for norepinephrine. Thus, in this animal model, the skin is cold due to denervation supersensitivity of adrenoceptors rather than excessive sympathetic vasoconstrictor activity.

Sympathetic denervation and denervation hypersensitivity cannot completely account for vasomotor and sudomotor abnormalities in CRPS. First of all, in CRPS I there is no overt nerve lesion. ${ }^{69}$ Furthermore, in CRPS II the autonomic symptoms spread beyond the territory of the lesioned nerve.

Studies on skin blood flow and temperature in CRPS I demonstrated that the warmer affected extremity in the acute stage of the disease $(<6$ months) is due to a functional inhibition of cutaneous sympathetic vasoconstrictor activity, leading to cutaneous vasodilatation. ${ }^{24,25}$ Consistently, direct measure- 
ments of norepinephrine levels from the venous effluent above the area of pain show a reduction in the affected extremity. ${ }^{24,25,70,71}$ These data support the idea that CRPS I is associated with disturbed sympathetic reflex patterns in the affected extremity. ${ }^{20,22}$ The locus of pathophysiological changes underlying such disturbed reflex activity must be in the central nervous system. Abnormalities in central autonomic control are consistent with experimental findings in animals, which show that the reflex pattern in single cutaneous vasoconstrictor neurons may change after peripheral nerve injury. ${ }^{64,72}$

Measurements of skin temperature and blood flow over time demonstrated a change according to the duration of CRPS. ${ }^{21}$ In more advanced stages $(>6$ months), there is an increased number of patients in whom skin temperature and blood flow in the affected limb are decreased. ${ }^{25}$ There is evidence that cutaneous sympathetic vasoconstrictor activity returns with the duration of the disease. ${ }^{24}$

The initial functional inhibition of vasoconstrictor activity in the acute stage might have led to secondary end-organ supersensitivity (decentralization supersensitivity) in the absence of structural damage to sympathetic fibers. ${ }^{62,66,69,73}$ Such supersensitivity could lead to increased vasoconstriction and reduced skin temperature, even though sympathetic postganglionic neuron activity is reduced. In fact, alpha-adrenoceptor density has been reported to be increased in skin biopsies of patients with CRPS. ${ }^{74,75}$ Accordingly, the few microneurographic studies of small sympathetic nerve fascicles that have been performed so far in patients with chronic CRPS with cold affected limbs showed that the average skin sympathetic activity was not different between the affected and contralateral side. ${ }^{76,77}$

Further important signs of sympathetic dysfunction in CRPS are unilateral sweating abnormalities. ${ }^{78}$ Quantitative measurements of sudomotor activity show enhanced sweat production in the disturbed limb in the acute and chronic stage of the disease in many CRPS patients. ${ }^{23,26}$ This unilateral hyperhidrosis indicates enhanced sympathetic sudomotor activity.

In conclusion, the combination of increased sudomotor and decreased cutaneous sympathetic vasoconstrictor outflow is a well known centrally regulated thermoregulatory function to keep body core temperature constant in different environments. However, under physiological conditions all extremities are involved. Therefore, the unilateral activation of sudomotor and inhibition of cutaneous sympathetic vasoconstrictor neurons indicates a centrally located thermoregulatory dysfunction in CRPS.

Sympathetically maintained pain Under physiological conditions there is no interaction between the sympathetic and the afferent nociceptive system; stimulation of the sympathetic trunk does not induce any activity in afferent neurons. ${ }^{65,79}$ However, under pathophysiological conditions the situation dramatically changes. ${ }^{80}$ Neurophysiological and neuroanatomical experiments in animals show that a pathologic coupling of sympathetic and afferent activity may follow a mechanically induced peripheral nerve lesion. This may take place between sympathetic fibers and regenerating or intact nociceptive $\mathrm{C}$-fibers in the periphery, or between sympathetic vasoconstrictor fibers and afferent somata within the dorsal root ganglion. ${ }^{81}$ The interaction is chemically via noradrenaline from sympathetic endings and adrenoreceptors that are expressed on afferent neurons under pathophysiological conditions (Figure 4A). Accordingly, mRNA for alpha $2 \mathrm{~A}^{-a d r e n o c e p t o r s ~ i s ~}$ up-regulated in DRG neurons after nerve lesion. ${ }^{82}$

Clinical studies in humans support the idea that nociceptors develop catecholamine sensitivity after complete or partial nerve lesions. After limb amputation, injection of epinephrine around a stump neuroma is reported to be intensely painful. ${ }^{83,84}$

Furthermore, intraoperative stimulation of the sympathetic chain induces an increase of spontaneous pain in patients with CRPS II but not in patients with hyperhidrosis. ${ }^{85,86}$ In CRPS and post-traumatic neuralgias, intracutaneous application of norepinephrine into a symptomatic area rekindled spontaneous pain and dynamic mechanical hyperalgesia that had been relieved by sympathetic blockade, supporting the idea
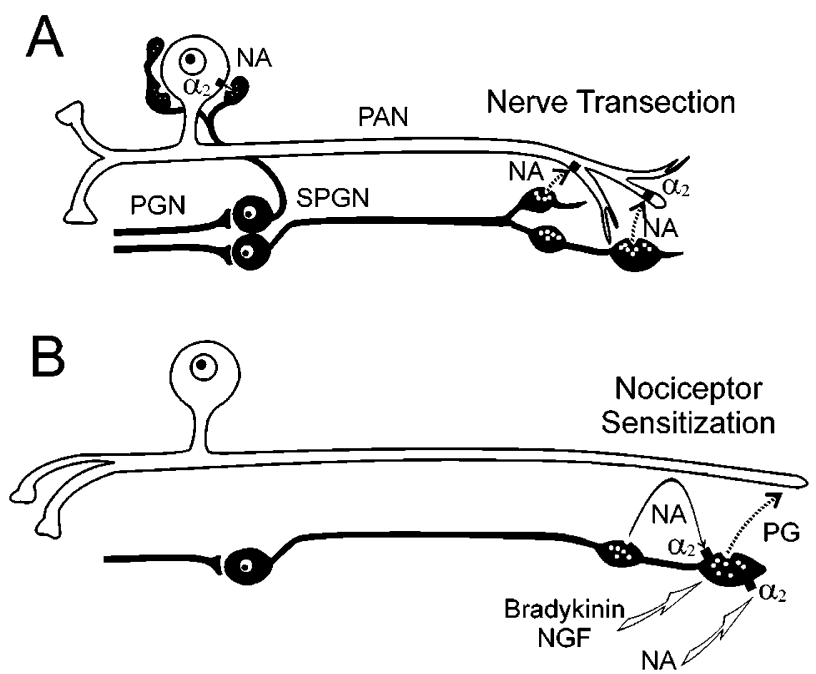

Figure 4 Influence of sympathetic activity and catecholamines on primary afferent neurons (PAN). (A) After nerve transection a sympathetic-afferent interaction occurs in the neuroma and in the dorsal root ganglion. It is mediated by norepinephrine (NA) released from sympathetic postganglionic neurons (SPGN) and $\alpha$-adrenoreceptors expressed at the plasma membrane of afferent neurons. PGN, preganglionic neuron. (B) After tissue inflammation intact but sensitized primary afferents acquire norepinephrine sensitivity. Norepinephrine is not acting directly on afferents but induces the release of prostaglandins (PG) from sympathetic terminals that sensitize the afferents. In accordance, bradykinin and nerve growth factor (NGF) induced nociceptor sensitization is also mediated by the release of prostaglandins from sympathetic postganglionic neurons. Adapted from ${ }^{169}$, with permission 
that noradrenergic sensitivity of human nociceptors is present after a partial nerve lesion. ${ }^{87}$ Also, in postherpetic neuralgia, spontaneous pain and mechanical hyperalgesia are enhanced after injection of epinephrine or phenylephrine. ${ }^{88} \mathrm{~A}$ potential criticism of the above mentioned studies, where pain was rekindled with exogenous adrenergic agonists, is that the doses of norepinephrine (NE) used were much higher than are likely to exist in vivo. Therefore, the algesic effects of peripheral administration of NE in physiologically relevant doses was compared in patients with SMP and normal subjects. ${ }^{89}$ Intradermal $\mathrm{NE}$, in physiologically relevant doses, was demonstrated to evoke greater pain in the affected regions of patients with SMP, than in the contralateral unaffected limb, and in control subjects. In accordance with this, spontaneous pain and dynamic as well as punctate mechanical hyperalgesia was augmented in patients with CRPS I when sympathetic cutaneous vasoconstrictor neurons were activated physiologically by thermoregulatory and respiratory stress. ${ }^{90,91}$ Interestingly, this applies also to acute CRPS patients who demonstrate a functional inhibition of cutaneous sympathetic vasoconstrictor activity in the affected extremity (see above). This is not necessarily a paradox, because a reduced sympathetic activity might be sufficient to maintain the pain, in particular if functional $\alpha$-adrenoceptors at the membrane of intact afferent fibers are up-regulated acutely. Furthermore, animal experiments have demonstrated that the sympathetic influence on inflammatory processes does not depend on sympathetic activity itself, but on the anatomical integrity of postganglionic fibers. ${ }^{92}$

\section{Peripheral inflammation}

Paul Sudeck postulated an exaggerated inflammatory response as an important pathophysiological mechanism in CRPS. ${ }^{6}$

Indeed, some of the clinical features of CRPS, particularly in its early phase, could be explained by an inflammatory process. ${ }^{93-95}$ Consistent with this idea, corticosteroids are often successfully used in acute CRPS. ${ }^{96}$

There is increasing evidence that a localized neurogenic inflammation might be involved in the generation of acute edema, vasodilatation and increased sweating. Scintigraphic investigations with radiolabelled immunoglobulins show extensive plasma extravasation in patients with acute CRPS I. ${ }^{10}$ Analysis of joint fluid and synovial biopsies in CRPS patients have shown an increase in protein concentration, synovial hypervascularity, and neutrophil infiltration. $^{97-99}$ Furthermore, synovial effusion is enhanced in affected joints as measured with MRI. ${ }^{100}$ In acute untreated CRPS I patients protein extravasation elicited by strong transcutaneous electrical stimulation was only provoked on the affected extremity as compared with the normal side, indicating that substance $\mathrm{P}$ might be involved. ${ }^{101}$
As further support of a neurogenic inflammatory process, serum concentrations of calcitonin gene-related peptide were elevated in CRPS patients as a marker for neurogenic inflammation. ${ }^{102}$ Venous blood samples of the affected extremity showed increased cytocine levels of interleukin-6 and tumor necrosis-alpha as evidence for a local inflammation. ${ }^{103}$ The production of nitric oxide in peripheral blood monocytes was significantly increased after stimulation with interferon-gamma in patients compared with controls. ${ }^{104}$

Thus the weight of evidence indicates that inflammatory processes are involved in the pathogenesis of early CRPS. However, the exact mechanisms of the initiation and maintenance of these inflammatory reactions are still far from clear. The central issue is whether there is a sympathetic as well as an inflammatory component and whether the sympathetic nervous system may contribute to the early inflammatory state. Animal studies have demonstrated that the sympathetic nervous system can influence the intensity of an inflammatory process, ${ }^{105,106}$ and studies indicate that sympatholytic procedures can ameliorate both pain and inflammation in humans (Figure 4B). ${ }^{107}$ However, this concept has yet to be proven in patients with CRPS.

\section{The central nervous system}

Autonomic disturbances indicate a centrally located thermoregulatory dysfunction in CRPS (see The sympathetic nervous system). Also other symptoms of CRPS I favour a central origin of the disorder, or at least a substantial role of central pathways. Impairment of muscle strength involving all muscles of the affected distal extremity that is not due to pain, oedema or severance of peripheral nerves is likely to be the result of a centrally mediated impulse abnormality in the motorneurone pool. Furthermore, patients complain about a neglect-like syndrome responsible for severe motor dysfunctions. ${ }^{108,109}$ In about $50 \%$ of the patients an increased physiological tremor is found that is due to central changes. ${ }^{28}$ Kinematic analysis of the upper extremity in CRPS revealed motor deficits probably due to impaired integration of visual and sensory afferent inputs to the partietal cortex. ${ }^{110}$

Based on numerous animal experimental findings, spontaneous pain and various forms of hyperalgesia at the distal extremity ${ }^{16,111}$ are thought to be generated by processes of peripheral and central sensitization (for review see ${ }^{112}$ ). Clinical and quantitative sensory testing of the nociceptive system demonstrated hemisensory impairment and hyperalgesia that frequently extends far beyond the area affected by spontaneous pain, indicating changes in central afferent processing that have been recently demonstrated by functional imaging studies. ${ }^{16-18,113-115}$ Furthermore, it is suggested that prefrontal networks are involved in SMP in CRPS patients. ${ }^{116}$ In one chronic CRPS patient symptoms resolved after a traumatic cerebral contusion in the left temporal lobe. ${ }^{117}$ 
All these data indicate that alterations of the central nervous system play an important role in CRPS. However, it is not clear, whether these are primary abnormalities in the disease or whether they are changes secondary to the pain.

\section{Genetic considerations}

The observation that many patients suffered from similar peripheral extremity trauma that is followed, in only a few by a CRPS, raises the question whether genetic factors are involved in the pathophysiology. Two studies revealed differences between CRPS patients and healthy controls in the human leukocyte antigen class II molecules encoded by genes of the human major histocompatibility complex on chromosome $6 .{ }^{118-120}$ The investigation of the innate cytokine profile in CRPS patients to determine a possible role of the immune system in the disease pathophysiology failed to show any significant results. ${ }^{121}$ The clinical relevance of these findings is not clear. The evidence of a facilitated neurogenic inflammation and an increased serum level of the neurogenic inflammatory peptide calcitonin gene-related peptide, even in the non-affected extremity, might indicate phenotypic differences between CRPS patients and controls. ${ }^{101,102}$

\section{Psychology of CRPS}

Most patients with CRPS exhibit a significant amount of psychological distress symptoms, with depression and anxiety being most common. Many patients become overwhelmed by the pain and associated symptoms. Without adequate psychosocial support the patients may develop maladaptive coping skills. These observations in connection with normal neurophysiological test results in CRPS I led to the hypothesis that CRPS is primarily a psychogenic disorder. $^{122,123}$ However, well designed studies and comprehensive reviews of the available literature have suggested that psychological symptoms are the result and not the cause of CRPS. ${ }^{124-127}$

\section{Diagnosis of CRPS and additional diagnostic tests}

For the present the diagnosis of CRPS is based on the clinical criteria described above. Procedures should start with taking a detailed medical history considering an initiating trauma and any history of sensory, autonomic and motor disturbances. One should explicitly ask for the development, time course, distribution and characteristics of pain. A general neurological examination is needed. Detection of any swelling, sweating, trophic, temperature and motor abnormality in the disturbed area is important. Muscle strength of the affected limb, as well as characteristics and distribution of somatosensory abnormalities, should be investigated in detail. One should test if the pain can be elicited by movements and pressure at the joints. Such an approach, according to the standardized diagnostic criteria for CRPS, is important in order to provide an accurate and complete description of patients' characteristics. ${ }^{128}$

Furthermore, many tests and procedures are valuable diagnostic tools that can add information to confirm the diagnostic impression about autonomic, sensory and motor function and dysfunction.

\section{Bone scintigraphy}

Bone scintigraphy can provide information about vascular bone changes, ${ }^{129}$ but it should be noted that bone scintigraphy is only positive for significant changes during the subacute period (up to 1 year). Especially, pathological uptake in the metacarpophalangeal joints and metacarpal bones in phase three of the three-phase bone scintigram are described as highly sensitive and specific for CRPS (Figure 5). ${ }^{130}$ It is therefore often applied to differentiate CRPS from other pain causes after central lesion. ${ }^{39}$ However, there is no known gold standard against which to compare this test.

\section{Plain radiographs}

These could be used to evaluate the status of mineralization, but are only positive in chronic stages.

\section{Quantitative sensory testing (QST)}

Psychophysical testing of thermal and thermal pain thresholds can provide information about the function or dysfunction of unmyelinated and small myelinated afferent fibers that project into the spinothalamic tracts. QST can also analyse the functional status of large myelinated fibers projecting to the dorsal columns by vibratory threshold testing. ${ }^{44,15,78,131,132}$ However, there seems to be no sensory profile that is characteristic for CRPS.

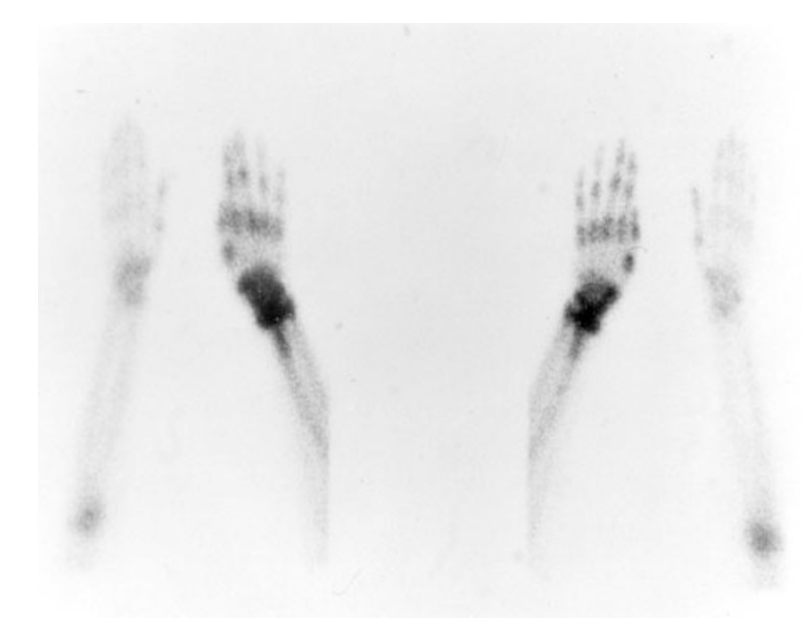

Figure 5 Three-phase bone scan in acute CRPS. In phase three a diffuse increase in tracer-uptake is found around the distal joints of the disturbed extremity. Adapted from ${ }^{170}$, with permission 


\section{Autonomic function}

This can be tested by a variety of new and emerging methods. These are infrared thermometry, laser Doppler flowmetry, ${ }^{20,22,133}$ infrared thermography ${ }^{134,135}$ and a quantitative sudomotor axon reflex test (QSART). ${ }^{19,23,26}$ Skin temperature differences may be helpful for diagnosis of CRPS. These typical temperature side differences are no static descriptors but comprise dynamic changes critically depending on environmental temperature and are most prominent at a high to medium level of sympathetic vasoconstrictor activity (Figure 6). ${ }^{25,136}$ Under resting conditions sensitivity of skin temperature asymmetries was only $32 \%$ compared with healthy controls. However, during experimental alteration of sympathetic activity by whole-body cooling and warming with a thermal suit, temperature differences between both sides increased dynamically in CRPS patients but not in controls, so that the sensitivity increased up to $76 \%$. A skin temperature asymmetry of more than $2.2^{\circ} \mathrm{C}$ had a specificity of $93 \%$ compared with patients suffering from painful limbs of other origin (Figure 6). ${ }^{136}$ Autonomic testing with the QSART can provide information about the function of sudomotor reflex loops. Swelling can be quantified by measuring water displacement.

\section{Differential diagnosis of CRPS}

The current CRPS diagnostic criteria are adequately sensitive (ie, rarely miss a case of actual CRPS). However, both internal and external validation research suggests that CRPS is currently overdiagnosed, despite the discrepancy that it is often recognized too late by general practitioners. $5,36,38$ Probable reasons are that there is no test available as
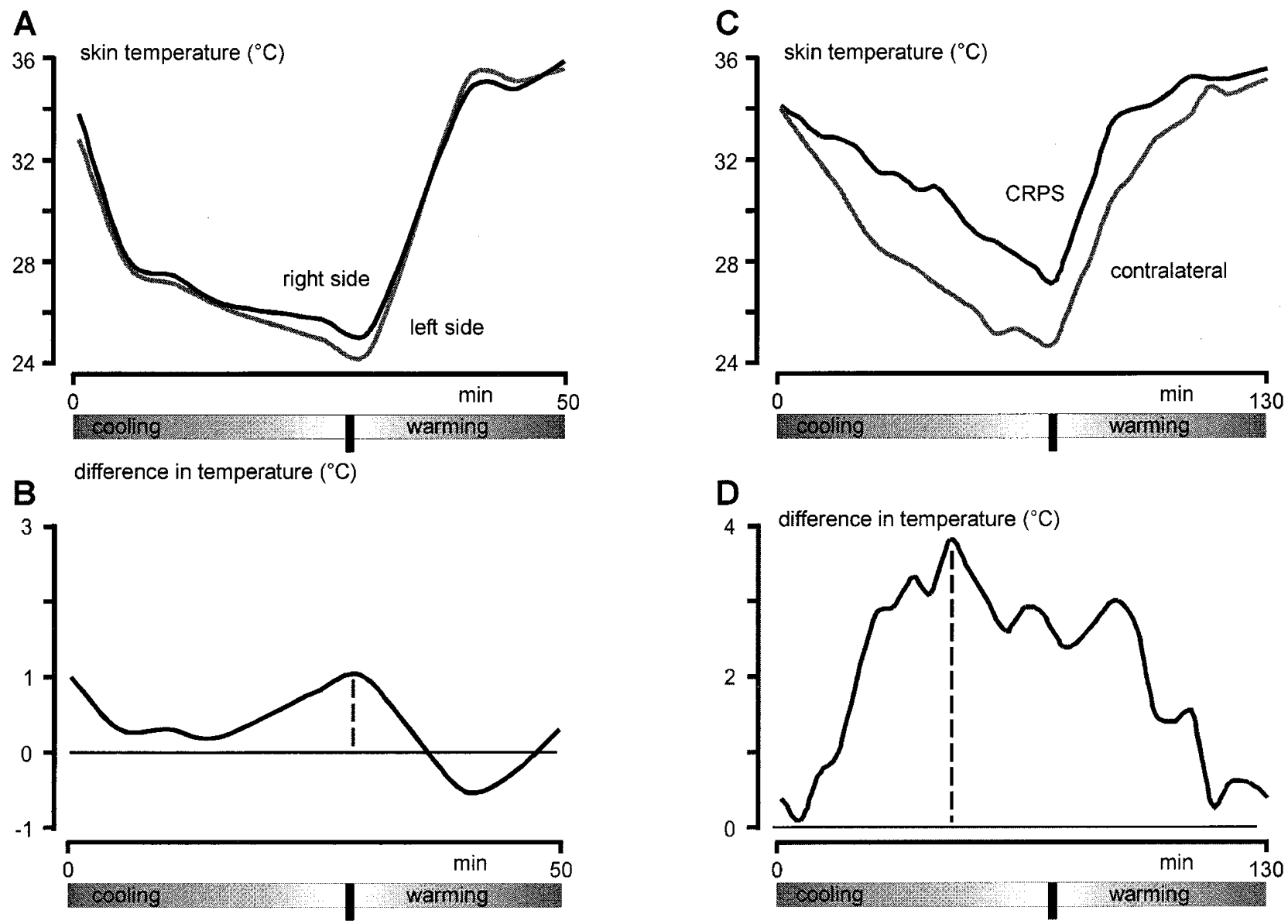

Figure 6 Characteristics of interside skin temperature differences during controlled alterations in sympathetic activity in CRPS. Controlled alterations of cutaneous sympathetic activity (whole-body cooling and warming) were applied by means of a thermal suit. The subject was lying in a suit supplied by tubes, in which running water of $12^{\circ} \mathrm{C}$ and $50^{\circ} \mathrm{C}$, respectively was used to cool (increase of sympathetic activity) or warm (inhibition of sympathetic activity) the whole body. The skin temperature of the fingers of both hands was monitored. (A) Temperature of the right and left hand in a healthy subject (C) Affected and healthy extremity in a CRPS patient. Side differences in skin temperature of the fingers of both hands in the healthy control subject (B) and in the CRPS patient (D) during controlled alterations of sympathetic activity. The arrow indicates beginning of whole-body warming. Maximal skin temperature differences during whole-body warming are indicated by the vertical dotted lines. Adapted from $^{136}$, with permission 
a gold standard and many other clinical entities are included under the umbrella of CRPS. ${ }^{8,37}$ Therefore, one should always search for the full picture of CRPS, including all clinical criteria and the typical medical history described above. In case of doubt other diseases that may cause neuropathic pain should be excluded. Furthermore, one should be aware of disorders causing pain and unilateral vascular changes such as inflammation or infections (eg, rheumatism, ulceration) and unilateral vascular occlusive diseases. Differential diagnostic problems might also be due to repetitive artificial occlusion of the blood supply to one limb as in a malingering or factitious disorder that needs a detailed psychological exploration.

\section{Therapeutic options for CRPS}

Lack of understanding of the underlying pathophysiological abnormalities and lack of objective diagnostic criteria resulted in inherent difficulties of conducting clinical trials with therapeutic modalities. Therefore, only few evidence-based treatment regimens for CRPS are available so far. In fact, three literature reviews of outcome studies find discouragingly little consistent information regarding the pharmacological agents and methods for treatment of CRPS. ${ }^{137,138}$ In the absence of more specific information about pathophysiological mechanisms and treatment of CRPS one has to rely on outcomes from treatment studies for other neuropathic pain syndromes. Furthermore, the still hypothetical mechanism-based treatment concept has to be transferred from ideas derived from animal experiments on peripheral nerve lesions to the situation in CRPS patients. Therefore, the following treatment options should be considered as a recommendation based on clinical evidence.

\section{General rules}

Treatment of CRPS requires a multidisciplinary approach including neurologists, anesthesiologists, orthopedic specialists, physiotherapists and psychologists. Treatment should be immediate, and most importantly directed toward restoration of full function of the extremity. The general principles of pharmacological treatment are the individualization of therapy and the titration of a given pharmacological agent, depending on the effect on one hand and side effects on the other. 'No-response' should not be accepted until a sufficient period of time has passed to judge the efficacy of the drug. Destructive surgery of the peripheral or central afferent nervous system in cases of CRPS always implies further deafferentation and thereby provides an increased risk for a persistent deafferentation type of pain.

\section{Pharmacological therapy}

Nonsteroidal anti-inflammatory drugs (NSAIDs) have not been demonstrated to have significant analgesic effect in treatment of CRPS, however, NSAIDs could be used for relief of mild to moderate pain.

Opioids strongly inhibit central nociceptive neurons mainly through interaction with $\mu$-receptors. Opioids are clearly effective in postoperative, inflammatory and cancer pain. The use of opioids in CRPS has not been studied. In other neuropathic pain syndromes intravenous morphine is clearly analgesic when compared to placebo. ${ }^{139}$ However, there are no long-term studies of oral opioids in the treatment of neuropathic pain, CRPS included. Even without solid scientific evidence the expert opinion of pain clinicians is that opioids could be, and should be, used as a part of a comprehensive pain treatment program. Given that some patients with neuropathic pain may obtain considerable pain relief, opioids should be tested early in the course of CRPS, and a trial of opioids should not be delayed to the 'last resort' status. Administration of opioids requires specific treatment programs for patients with a history of chemical dependence and caution in patients with pulmonary disease. Prophylactic treatment of common side-effects, notably nausea or constipation, can improve patients' compliance.

Tricyclic antidepressants (TCA) are the best studied group of pharmacological agents in neuropathic pain and they have shown an analgesic effect. TCA inhibit re-uptake of monoaminergic transmitters. There is solid evidence that the re-uptake blocker of serotonin and noradrenaline amitriptyline and the selective noradrenaline blocker desipramine produce pain relief in diabetic or postherpetic neuropathy. ${ }^{140-142}$ The mean dose that is often sufficient for pain reduction (eg amitriptyline $75-150 \mathrm{mg} /$ day) is smaller than doses necessary to achieve anti-depressant effects. Onset of the analgesic effect occurs within 1-2 weeks and peaks around 4-6 weeks. ${ }^{141}$ Improvement of sleep, mood and anxiety can further add to the pain relieving action.

Sodium blocking agents, the type Ib anti-arrhythmic drugs lidocaine, mexiletine and tocainide, and the anticonvulsant carbamazepine have an effect on sodium channels and potentially relieve neuropathic pain. ${ }^{139,143}$ Intraveneous lidocaine was effective in CRPS. ${ }^{144}$ Care needs to be taken when administering these compounds. Contra-indications include electrocardiac abnormalities, reduced left ventricular function and coronary heart disease.

GABA-agonists such as baclofen, valproic acid, vigabatrine and benzodiazepines interacting with GABAergic transmission have been reported to alleviate different neuropathic pain conditions. The general clinical impression is that such drugs do not provide substantial pain relief, except for baclofen in trigeminal neuralgia. Some agents may have a place in the treatment of painful muscle spasms.

The action of the drug gabapentin is not completely resolved, but probably includes an inhibition of calcium channels. In one study, gabapentin had a promising effect on CRPS. ${ }^{145}$ 
There are many uncontrolled surveys in the

Glucocorticoids taken orally are the category of agents that has clearly demonstrated efficacy in controlled trials. ${ }^{96}$ There is no evidence that other immune-modulating therapies, notably intravenous immunoglobulins or immunosuppressive drugs have a place in the treatment of CRPS.

Transdermal application of the $\alpha_{2}$-adrenoceptor agonist clonidine, which is thought to prevent the release of catecholamines by a presynaptic action, may be helpful when small areas of hyperalgesia are present. ${ }^{146,147}$

Clinically available compounds that are demonstrated to have NMDA receptor blocking properties include ketamine, dextromethorphane and memantine. They offer new options for treatment of CRPS pain, but studies which will help clinicians to fully utilize these agents are not available.

Subcutaneous calcitonin only had a mild effect on spontaneous pain. ${ }^{148}$ Intravenous bisphosphonates (alendronate, clodronate), however, showed a significant improvement in pain, swelling and movements. ${ }^{149,150}$

\section{Interventional therapy at the sympathetic nervous} system

Interruption of the sympathetic nerve supply to the affected extremity has been used to treat CRPS for many years. Proof of the effectiveness of sympathetic blockade, however, is scanty. ${ }^{137,151}$ Some authors even discard the concept that the sympathetic nervous system is actively involved in the generation of pain. ${ }^{122,152}$ They claim that interventions that block sympathetic activity lack specificity, and argue that the techniques and results of sympathetic blockade have rarely been adequately evaluated and are in most cases not placebo-controlled.

Currently, two therapeutical techniques to block sympathetic nerves are used: (1) injections of a local anaesthetic around sympathetic paravertebral ganglia that project to the affected body part (sympathetic ganglion blocks); and (2) regional intravenous application of guanethidine, bretylium or reserpine (which all deplete noradrenaline in the postganglionic axon) to an isolated extremity blocked with a tourniquet (intravenous regional sympatholysis, IVRS).

Although sympatholytic therapy can frequently result in substantial or even complete pain relief, blockade of the sympathetic activity is ineffective in some patients. Nonetheless, with all of the shortcomings there is a compelling historical and basic and clinical science evidence that it is important that an adequate sympatholytic trial by a qualified clinician should be performed in an attempt to differentiate between SMP and SIP. In the presence of a significant sympathetic component, treatment strategies towards the sympathetic therapy could be considered. Beside the pain, other symptoms may improve after sympathetic blocks. literature reviewing the effect of sympathetic interventions in CRPS and post-traumatic neuralgias. In CRPS, about $85 \%$ of the patients report a positive acute effect, but fewer patients experience long-term relief $(60 \%$ in sympathetic block and $30 \%$ in intravenous regional sympatholysis). In post-traumatic neuralgias the sympatholytic interventions are clearly less effective. One controlled study in patients with CRPS I has shown that sympathetic blockade with local anaesthetic has the same immediate effect on pain as a control injection with saline. ${ }^{153}$ However, after 24 hours patients in the local anaesthetic group were much better, indicating that non-specific effects are important initially and that evaluating the efficacy of sympatholytic interventions is best done after one day. Interestingly, one prospective study showed that perioperative stellate ganglion blocks in patients with a history of CRPS can significantly reduce the recurrence rate of this disease. ${ }^{154}$ Controlled studies using guanethidine IVRS did not show a beneficial effect. ${ }^{155-157}$

In our view, there is a desperate need for controlled studies that assess the acute as well as the long-term effect of sympathetic blockade on pain and other CRPS symptoms, in particular motor function. Well performed sympathetic ganglion blocks should be performed rather than IVRS.

\section{Stimulation techniques and spinal drugs application}

Transcutaneous electrical nerve stimulation (TENS) may be effective in some cases and has minimal side effects. Epidural spinal cord stimulation (SCS) has shown efficacy in one randomized study in selected chronic CRPS patients ${ }^{158,159}$ and may be a promising treatment for this group of patients. Interestingly, these patients had undergone previous unsuccessful surgical sympathectomy. The pain relieving effect was not associated with peripheral vasodilatation suggesting that central disinhibition processes are involved. ${ }^{160}$ Sensory detection threshold were not effected by the stimulation. ${ }^{161}$ Other stimulation techniques, ie peripheral nerve stimulation with implanted electrodes, and deep brain stimulation (sensory thalamus and medial lemniscus), have been reported to be effective in selected cases of CRPS. ${ }^{162}$

Also in selected patients with severe refractory CRPS, epidural administration of clonidine or the NMDA-antagonist ketamine induced analgesia associated with marked side-effects like sedation and hypotension. ${ }^{163,164}$ Intrathecal baclofen demonstrated a positive outcome for CRPS patients with severe dystonia. ${ }^{165}$

\section{Physical therapy}

Clinical experience and two prospective studies indicate that physiotherapy is of utmost importance to achieve recovery of function and rehabilitation. ${ }^{166-168}$ At the 
acute stage of CRPS when the patients still suffer from severe pain, it is mostly impossible to carry out intensive active therapy. Painful interventions and in particular aggressive physical therapy at this stage leads to deterioration. Therefore, immobilization and careful contralateral physical therapy should be the acute treatment of choice. Later, when pain subsides, passive physical therapy, active isometric followed by active isotonic training should be performed in combination with sensory desensitization programs.

\section{Acknowledgements}

This work was supported by the Deutsche Forschungsgemeinschaft (DFG Ba 1921/1-1) and the BMBF Network 'Neuropathic Pain'.

\section{References}

1 Wasner G, Backonja MM, Baron R. Traumatic Neuralgias: Complex Regional Pain Syndromes (Reflex Sympathetic Dystrophy and Causalgia): Clinical Characteristics, Pathophysiological Mechanisms and Therapy. Neurol Clin 1998; 16: 851-868.

2 Stanton-Hicks M, Jänig W, Hassenbusch S, Haddox JD, Boas R, Wilson P. Reflex sympathetic dystrophy: changing concepts and taxonomy. Pain 1995; 63: $127-$ 133.

3 Merskey H, Bogduk N. Classification of chronic pain: descriptions of chronic pain syndromes and definition of terms. Seattle: IASP Press, 1995.

4 Harden RN, Baron R, Jänig W. Complex regional pain syndrome, Vol. 22, Progress in Pain Research and Management. Seattle: IASP Press, 2001.

5 Allen G, Galer BS, Schwartz L. Epidemiology of complex regional pain syndrome: a retrospective chart review of 134 patients. Pain 1999; 80: 539-544.

6 Sudeck P. Über die akute (trophoneurotische) Knochenatrophie nach Entzündungen und Traumen der Extremitäten. Deut Med Wschr 1902; 28: 336-342.

7 van der Laan L et al. Complex regional pain syndrome type I (RSD): pathology of skeletal muscle and peripheral nerve. Neurology 1998; 51: 20-25.

8 Schott GD. Reflex sympathetic dystrophy. J Neurol Neurosurg Psychiatry 2001; 71: $291-295$.

9 Schwartzman RJ, McLellan TL. Reflex sympathetic dystrophy. A review. Arch Neurol 1987; 44: 555-561.

10 Oyen WJ et al. Reflex sympathetic dystrophy of the hand: an excessive inflammatory response? Pain 1993; 55: $151-157$.

11 Blumberg H, Jänig W. Clinical manifestation of reflex sympathetic dystrophy and sympathetically maintained pain. In: Wall and Melzack (eds). Textbook of Pain. Edinburgh: Churchill Livingstone, 1994; pp 685-697.

12 Veldman PHJM. Clinical aspects of reflex sympathetic dystrophy. Thesis, Nijmegen, 1995.

13 Galer BS, Jensen MP. Development and preliminary validation of a pain measure specific to neuropathic pain: the Neuropathic Pain Scale. Neurology 1997; 48: $332-338$.
14 Price DD, Bennett GJ, Rafii A. Psychophysical observations on patients with neuropathic pain relieved by a sympathetic block. Pain 1989; 36: 273-288.

15 Price DD, Long S, Huitt C. Sensory testing of pathophysiological mechanisms of pain in patients with reflex sympathetic dystrophy. Pain 1992; 49: 163-173.

16 Sieweke $\mathrm{N}$ et al. Patterns of hyperalgesia in complex regional pain syndrome. Pain 1999; 80: 171-177.

17 Rommel O, Malin JP, Zenz M, Jänig W. Quantitative sensory testing, neurophysiological and psychological examination in patients with complex regional pain syndrome and hemisensory deficits. Pain 2001; 93: $279-$ 293.

18 Rommel $\mathrm{O}$ et al. Hemisensory impairment in patients with complex regional pain syndrome. Pain 1999; 80: 95-101.

19 Chelimsky TC et al. Value of autonomic testing in reflex sympathetic dystrophy. Mayo Clin Proc 1995; 70: 1029 1040.

20 Baron R, Maier C. Reflex sympathetic dystrophy: skin blood flow, sympathetic vasoconstrictor reflexes and pain before and after surgical sympathectomy. Pain 1996; 67: $317-326$.

21 Wasner G, Drummond P, Birklein F, Baron R. The role of the sympathetic nervous system in autonomic disturbances and 'sympathetically maintained pain' in CRPS. In: Harden RN, Baron R, Jänig W (eds). Progress in Pain Research and Management, Vol. 22, Complex regional pain syndrome. Seattle: IASP Press, 2001; pp 89-118.

22 Birklein F, Riedl B, Neundörfer B, Handwerker HO. Sympathetic vasoconstrictor reflex pattern in patients with complex regional pain syndrome. Pain 1998; 75: $93-100$.

23 Birklein F et al. Sudomotor function in sympathetic reflex dystrophy. Pain 1997; 69: 49-54.

24 Wasner G, Heckmann K, Maier C, Baron R. Vascular abnormalities in acute reflex sympathetic dystrophy (CRPS I): complete inhibition of sympathetic nerve activity with recovery. Arch Neurol 1999; 56: 613-620.

25 Wasner $\mathrm{G}$ et al. Vascular abnormalities in reflex sympathetic dystrophy (CRPS I): mechanisms and diagnostic value. Brain 2001; 124: $587-599$.

26 Low PA et al. Laboratory findings in reflex sympathetic dystrophy: a preliminary report. Clin J Pain 1994; 10: $235-239$.

27 Schwartzman RJ, Kerrigan J. The movement disorder of reflex sympathetic dystrophy. Neurology 1990; 40: $57-61$

28 Deuschl G, Blumberg H, Lücking $\mathrm{CH}$. Tremor in reflex sympathetic dystrophy. Arch Neurol 1991; 48: $1247-$ 1252.

29 Bhatia KP, Bhatt MH, Marsden CD. The causalgiadystonia syndrome. Brain 1993; 116: 843 - 851 .

30 Marsden CD et al. Muscle spasms associated with Sudeck's atrophy after injury. $\mathrm{Br}$ Med J (Clin Res Ed) 1984; 288: $173-176$.

31 Evans JA. Reflex sympathetic dystrophy. Surg Clin North Am 1946; 26: 435 - 448.

32 Pak TJ, Martin GM, Magness JL, Kavanaugh GJ. Reflex sympathetic dystrophy. Review of 140 cases. Minn Med 1970; 53: 507-512.

33 Mitchell SW. Injuries of Nerves and their Consequences. New York: Dover, 1865. 
34 Richards RL. Causalgia. A centennial review. Arch Neurol 1967; 16: 339 - 350 .

35 Baron R, Jänig W. Pain syndromes with causal participation of the sympathetic nervous system. Anaesthesist 1998; 47: 4-23.

36 Harden RN et al. Complex regional pain syndrome: are the IASP diagnostic criteria valid and sufficiently comprehensive? Pain 1999; 83: $211-219$.

37 Galer BS, Bruehl S, Harden RN. IASP diagnostic criteria for complex regional pain syndrome: a preliminary empirical validation study. International Association for the Study of Pain. Clin J Pain 1998; 14: $48-54$

38 Bruehl S et al. External validation of IASP diagnostic criteria for Complex Regional Pain Syndrome and proposed research diagnostic criteria. International Association for the Study of Pain. Pain 1999; 81: 147 154.

39 Gellman $\mathrm{H}$ et al. Reflex sympathetic dystrophy in braininjured patients. Pain 1992; 51: 307-311.

40 Chalsen GG et al. Prevalence of the shoulder-hand pain syndrome in an in-patient stroke rehabilitation population: a quantitative cross-sectional study. $J$ Neurol Rehab 1987; 1: 137 - 141.

41 Petchkrua W, Weiss DJ, Patel RR. Reassessment of the incidence of complex regional pain syndrome type 1 following stroke. Neurorehabil Neural Repair 2000; 14: $59-63$.

42 Daviet JC et al. Clinical factors in the prognosis of complex regional pain syndrome type I after stroke: a prospective study. Am J Phys Med Rehabil 2002; 81: $34-39$.

43 Davis SW, Petrillo CR, Eichberg RD, Chu DS. Shoulder-hand syndrome in a hemiplegic population: a 5-year retrospective study. Arch Phys Med Rehabil 1977; 58: $353-356$.

44 Wanklyn P, Forster A, Young J, Mulley G. Prevalence and associated features of the cold hemiplegic arm. Stroke 1995; 26: $1867-1870$.

45 Korpelainen JT, Sotaniemi KA, Myllyla VV. Asymmetrical skin temperature in ischemic stroke. Stroke 1995; 26: $1543-1547$.

46 Butler SH. Disuse and CRPS. In: Harden RN, Baron R, Jänig W (eds). Progress in Pain Research and Management, Vol. 22, Complex regional pain syndrome. Seattle: IASP Press, 2001; pp $141-150$.

47 Riedl B et al. Autonomic failure after stroke - is it indicative for pathophysiology of complex regional pain syndrome? Acta Neurol Scand 2001; 103: $27-34$.

48 Braus DF, Krauss JK, Strobel J. The shoulder-hand syndrome after stroke: a prospective clinical trial. Ann Neurol 1994; 36: $728-733$.

49 Fenollosa $\mathrm{P}$ et al. Chronic pain in the spinal cord injured: statistical approach and pharmacological treatment. Paraplegia 1993; 31: $722-729$.

50 Waring WP, Maynard FM. Shoulder pain in acute traumatic quadriplegia. Paraplegia 1991; 29: 37-42.

51 Andrews LG, Armitage KJ. Sudeck's atrophy in traumatic quadriplegia. Paraplegia 1971; 9: 159- 165.

52 Gellman $\mathrm{H}$ et al. Reflex sympathetic dystrophy in cervical spinal cord injury patients. Clin Orthop 1988; 233: $126-131$.

53 Subbarao J, Stillwell GK. Reflex sympathetic dystrophy syndrome of the upper extremity: analysis of total outcome of management of 125 cases. Arch Phys Med Rehabil 1981; 62: 549 - 554 .
54 Gallien $\mathrm{P}$ et al. The reflex sympathetic dystrophy syndrome in patients who have had a spinal cord injury. Paraplegia 1995; 33: $715-720$.

55 Philip PA, Philip M, Monga TN. Reflex sympathetic dystrophy in central cord syndrome: case report and review of the literature. Paraplegia 1990; 28: $48-54$.

56 Lefkoe TP, Cardenas DD. Reflex sympathetic dystrophy of the lower extremity in tetraplegia: case report. Spinal Cord 1996; 34: 239-242.

57 Cremer SA, Maynard F, Davidoff G. The reflex sympathetic dystrophy syndrome associated with traumatic myelopathy: report of 5 cases. Pain 1989; 37: $187-$ 192

58 Aisen PS, Aisen ML. Shoulder-hand syndrome in cervical spinal cord injury. Paraplegia 1994; 32: $588-$ 592

59 Dalyan M, Sherman A, Cardenas DD. Factors associated with contractures in acute spinal cord injury. Spinal Cord 1998; 36: 405-408.

60 Arnér S. Intravenous phentolamine test: diagnostic and prognostic use in reflex sympathetic dystrophy. Pain 1991; 46: $17-22$.

61 Raja SN, Treede RD, Davis KD, Campbell JN. Systemic alpha-adrenergic blockade with phentolamine: a diagnostic test for sympathetically maintained pain. Anesthesiology 1991; 74: 691-698.

62 Jänig W, McLachlan EM. Neurobiology of the autonomic nervous system. In: Mathias CJ, Bannister Sir R (eds). Autonomic failure - a textbook of clinical disorders of the autonomic nervous system. 4th edn. Oxford: Oxford University Press, 1999; pp 3-15.

63 Jänig W, Häbler HJ. Organization of the autonomic nervous system: structure and function. In: Vinken PJ, Bruyn GW (eds). Handbook of Clinical Neurology - The Autonomic Nervous System, Part I: Normal Functions. Amsterdam: Elsevier Science Publishers, 1999; pp 1-52.

64 Jänig W, Koltzenburg M. Sympathetic reflex activity and neuroeffector transmission change after chronic nerve lesions. In: Bond MR, Charlton EJ, Woolf CJ (eds). Proceedings of the VIth World Congress on Pain. Amsterdam: Elsevier Science Publishers, 1991; pp 365 371.

65 Baron $\mathrm{R}$ et al. Effect of sympathetic activity on capsaicin-evoked pain, hyperalgesia, and vasodilatation. Neurology 1999; 52: 923 - 932.

66 Fleming WW, Westfall DP. Adaptive supersensitivity. In: Trendelenburg U, Weiner N (eds). Handbook of Experimental Pharmacology, Vol. 90/I, Catecholamines. New York: Springer Verlag, 1988; pp 509-559.

67 Kurvers HA et al. Skin blood flow abnormalities in a rat model of neuropathic pain: result of decreased sympathetic vasoconstrictor outflow? J Auton Nerv Syst 1997; 63: $19-29$.

68 Wakisaka S, Kajander KC, Bennett GJ. Abnormal skin temperature and abnormal sympathetic vasomotor innervation in an experimental painful peripheral neuropathy. Pain 1991; 46: 299-313.

69 Goldstein DS, Tack C, Li ST. Sympathetic innervation and function in reflex sympathetic dystrophy. Ann Neurol 2000; 48: 49-59.

70 Drummond PD, Finch PM, Smythe GA. Reflex sympathetic dystrophy: the significance of differing plasma catecholamine concentrations in affected and unaffected limbs. Brain 1991; 114: 2025 - 2036. 
71 Harden RN et al. Norepinephrine and epinephrine levels in affected versus unaffected limbs in sympathetically maintained pain. Clin J Pain 1994; 10: 324-330.

72 Blumberg H, Jänig W. Reflex patterns in postganglionic vasoconstrictor neurons following chronic nerve lesions. J Auton Nerv Syst 1985; 14: 157-180.

73 Bossut DF, Shea VK, Perl ER. Sympathetectomy induces adrenergic excitability of cutaneous C-fiber nociceptors. J Neurophysiol 1996; 75: 514-517.

74 Drummond PD, Skipworth S, Finch PM. alpha 1adrenoceptors in normal and hyperalgesic human skin. Clin Sci (Colch) 1996; 91: 73 - 77.

75 Arnold JM et al. Increased venous alpha-adrenoceptor responsiveness in patients with reflex sympathetic dystrophy. Ann Intern Med 1993; 118: 619-621.

76 Casale R, Elam M. Normal sympathetic nerve activity in a reflex sympathetic dystrophy with marked skin vasoconstriction. J Auton Nerv Syst 1992; 41: 215-219.

77 Torebjörk E. Clinical and neurophysiological observations relating to pathophysiological mechanisms of reflex sympathetic dystrophy. In: Stanton-Hicks M, Jänig W, Boas RA (eds). Reflex sympathetic dystrophy. Boston, Dordrecht, London: Kluwer, 1989; pp 71-80.

78 Birklein $\mathrm{F}$ et al. Neurological findings in complex regional pain syndromes - analysis of 145 cases. Acta Neurol Scand 2000; 101: 262-269.

79 Elam M, Olausson B, Skarphedinsson JO, Wallin BG. Does sympathetic nerve discharge affect the firing of polymodal C-fibre afferents in humans? Brain 1999; 122: $2237-2244$

80 Jänig W, Levine JD, Michaelis M. Interactions of sympathetic and primary afferent neurons following nerve injury and tissue trauma. Prog Brain Res 1996; 113: $161-184$.

81 McLachlan EM, Jänig W, Devor M, Michaelis M. Peripheral nerve injury triggers noradrenergic sprouting within dorsal root ganglia. Nature 1993; 363: $543-546$.

82 Shi TS, Winzer-Serhan U, Leslie F, Hokfelt T. Distribution and regulation of alpha(2)-adrenoceptors in rat dorsal root ganglia. Pain 2000; 84: 319-330.

83 Chabal C, Jacobson L, Russell LC, Burchiel KJ. Pain response to perineuromal injection of normal saline, epinephrine, and lidocaine in humans. Pain 1992; 49: 9 12.

84 Raja SN, Abatzis V, Frank SM. Role of a-adrenoceptors in neuroma pain in amputees. Anesthesiology 1998; 89: A1083.

85 Walker AE, Nulsen F. Electrical stimulation of the upper thoracic portion of the sympathetic chain in man. Arch Neurol Psychiatr 1948; 59: 559-560.

86 White JC, Sweet WH. Pain and the neurosurgeon. Illinois: Charles C. Thomas Springfield, 1969.

87 Torebjörk E et al. Noradrenaline-evoked pain in neuralgia. Pain 1995; 63: $11-20$.

88 Choi B, Rowbotham MC. Effect of adrenergic receptor activation on post-herpetic neuralgia pain and sensory disturbances. Pain 1997; 69: 55-63.

89 Ali $\mathrm{Z}$ et al. Intradermal injection of norepinephrine evokes pain in patients with sympathetically maintained pain. Pain 2000; 88: $161-168$.

90 Baron $\mathrm{R}$ et al. Relation between sympathetic vasoconstrictor activity and pain and hyperalgesia in complex regional pain syndromes: a case-control study. Lancet 2002; 359: $1655-1660$.
91 Drummond PD, Finch PM, Skipworth S, Blockey P Pain increases during sympathetic arousal in patients with complex regional pain syndrome. Neurology 2001; 57: $1296-1303$.

92 Green PG, Jänig W, Levine JD. Negative feedback neuroendocrine control of inflammatory response in the rat is dependent on the sympathetic postganglionic neuron. J Neurosci 1997; 17: $3234-3238$.

93 Leitha $\mathrm{T}$ et al. Five phase bone scintigraphy supports the pathophysiological concept of a subclinical inflammatory process in reflex sympathetic dystrophy. $Q J$ Nucl Med 1996; 40: $188-193$.

94 Calder JS, Holten I, McAllister RM. Evidence for immune system involvement in reflex sympathetic dystrophy. J Hand Surg [Br] 1998; 23: 147-150.

95 van der Laan L, Goris RJ. Reflex sympathetic dystrophy. An exaggerated regional inflammatory response? Hand Clin 1997; 13: 373 - 385.

96 Christensen K, Jensen EM, Noer I. The reflex dystrophy syndrome response to treatment with systemic corticosteroids. Acta Chir Scand 1982; 148: 653-655.

97 Renier JC et al. The joint in algodystrophy. Joint fluid, synovium, cartilage. Rev Rhum Mal Osteoartic 1983; 50: $255-260$.

98 Kozin F, McCarty DJ, Sims J, Genant H. The reflex sympathetic dystrophy syndrome. I. Clinical and histologic studies: evidence for bilaterality, response to corticosteroids and articular involvement. Am J Med 1976; 60: $321-331$

99 Hannington-Kiff JG. Relief of Sudeck's atrophy by regional intravenous guanethidine. Lancet 1977; 1: $1132-1133$

100 Graif $\mathrm{M}$ et al. Synovial effusion in reflex sympathetic dystrophy: an additional sign for diagnosis and staging. Skeletal Radiol 1998; 27: 262-265.

101 Weber M, Birklein F, Neundorfer B, Schmelz M. Facilitated neurogenic inflammation in complex regional pain syndrome. Pain 2001; 91: $251-257$.

102 Birklein F, Schmelz M, Schifter S, Weber M. The important role of neuropeptides in complex regional pain syndrome. Neurology 2001; 57: 2179-2184.

103 Huygen FJ et al. Evidence for local inflammation in complex regional pain syndrome type 1. Mediators Inflamm 2002; 11: 47-51.

104 Hartrick CT. Increased production of nitric oxide stimulated by interferon-gamma from peripheral blood monocytes in patients with complex regional pain syndrome. Neurosci Lett 2002; 323: $75-77$.

105 Levine JD, Taiwo YO, Collins SD, Tam JK. Noradrenaline hyperalgesia is mediated through interaction with sympathetic postganglionic neurone terminals rather than activation of primary afferent nociceptors. Nature 1986; 323: $158-160$.

106 Perl ER. Cutaneous polymodal receptors: characteristics and plasticity. Prog Brain Res 1996; 113: 21 - 37.

107 Levine JD et al. Clinical response to regional intravenous guanethidine in patients with rheumatoid arthritis J Rheumatol 1986; 13: 1040 - 1043.

108 Galer BS, Butler S, Jensen MP. Case reports and hypothesis: a neglect-like syndrome may be responsible for the motor disturbance in reflex sympathetic dystrophy (Complex Regional Pain Syndrome-1). J Pain Symptom Manage 1995; 10: 385 - 391. 
109 Galer BS, Jensen M. Neglect-like symptoms in complex regional pain syndrome: results of a self-administered survey. J Pain Symptom Manage 1999; 18: 213-217.

110 Schattschneider J, Wenzelburger R, Deuschl G, Baron R. Kinematic analysis of the upper extremity in CRPS. In: Harden RN, Baron R, Jänig W (eds). Progress in Pain Research and Management, Vol. 22, Complex regional pain syndrome. Seattle: IASP Press, 2001; pp $119-128$.

111 Maleki J, LeBel AA, Bennett GJ, Schwartzman RJ Patterns of spread in complex regional pain syndrome, type I (reflex sympathetic dystrophy). Pain 2000; 88: $259-266$.

112 Woolf CJ, Mannion RJ. Neuropathic pain: aetiology, symptoms, mechanisms, and management. Lancet 1999 ; 353: $1959-1964$.

113 Juottonen $\mathrm{K}$ et al. Altered central sensorimotor processing in patients with complex regional pain syndrome. Pain 2002; 98: $315-323$.

114 Thimineur $\mathrm{M}$ et al. Central nervous system abnormalities in complex regional pain syndrome (CRPS): clinical and quantitative evidence of medullary dysfunction. Clin J Pain 1998; 14: 256-267.

115 Fukumoto $\mathrm{M}$ et al. Contralateral thalamic perfusion in patients with reflex sympathetic dystrophy syndrome. Lancet 1999; 354: $1790-1791$.

116 Apkarian AV, Thomas PS, Krauss BR, Szeverenyi NM. Prefrontal cortical hyperactivity in patients with sympathetically mediated chronic pain. Neurosci Lett 2001; 311: $193-197$.

117 Shibata M et al. A case of reflex sympathetic dystrophy (complex regional pain syndrome, type I) resolved by cerebral contusion. Pain 1999; 79: $313-315$.

118 Mailis A, Wade J. Profile of Caucasian women with possible genetic predisposition to reflex sympathetic dystrophy: a pilot study. Clin J Pain 1994; 10: 210 - 217.

119 Kemler MA et al. HLA-DQ1 associated with reflex sympathetic dystrophy. Neurology 1999; 53: 13501351.

120 Mailis A, Wade JA. Genetic considerations in CRPS In: Harden RN, Baron R, Jänig W (eds). Progress in Pain Research and Management, Vol. 22, Complex regional pain syndrome. Seattle: IASP Press, 2001; pp $227-238$

121 van de Beek WJ, Remarque EJ, Westendorp RG, van Hilten JJ. Innate cytokine profile in patients with complex regional pain syndrome is normal. Pain 2001; 91: $259-261$.

122 Ochoa JL. Truths, errors, and lies around 'reflex sympathetic dystrophy' and 'complex regional pain syndrome'. J Neurol 1999; 246: 875 - 879.

123 Verdugo RJ, Ochoa JL. Abnormal movements in complex regional pain syndrome: assessment of their nature. Muscle Nerve 2000; 23: $198-205$.

124 Ciccone DS, Bandilla EB, Wu W. Psychological dysfunction in patients with reflex sympathetic dystrophy. Pain 1997; 71: $323-333$.

125 Van Houdenhove B et al. Etiopathogenesis of reflex sympathetic dystrophy: a review and biopsychosocial hypothesis. Clin J Pain 1992; 8: $300-306$.

126 van der Laan L, van Spaendonck K, Horstink MW, Goris RJ. The Symptom Checklist-90 Revised questionnaire: no psychological profiles in complex regional pain syndrome-dystonia. J Pain Symptom Manage 1999; 17: $357-362$.
127 Geertzen JH et al. Stressful life events and psychological dysfunction in Complex Regional Pain Syndrome type I. Clin J Pain 1998; 14: 143-147.

128 van de Beek WJ et al. Diagnostic criteria used in studies of reflex sympathetic dystrophy. Neurology 2002; 58: $522-526$

129 Kozin $\mathrm{F}$ et al. Bone scintigraphy in the reflex sympathetic dystrophy syndrome. Radiology 1981; 138: $437-443$.

130 Zyluk A. The usefulness of quantitative evaluation of three-phase scintigraphy in the diagnosis of posttraumatic reflex sympathetic dystrophy. J Hand Surg [Br] 1999; 24: 16-21.

131 Wahren LK, Torebjork E, Nystrom B. Quantitative sensory testing before and after regional guanethidine block in patients with neuralgia in the hand. Pain 1991; 46: $23-30$.

132 Wahren LK, Torebjork E. Quantitative sensory tests in patients with neuralgia 11 to 25 years after injury. Pain 1992; 48: $237-244$.

133 Schürmann $\mathrm{M}$ et al. Assessment of peripheral sympathetic nervous function for diagnosing early posttraumatic complex regional pain syndrome type I. Pain 1999; 80: $149-159$.

134 Gulevich SJ et al. Stress infrared telethermography is useful in the diagnosis of complex regional pain syndrome, type I (formerly reflex sympathetic dystrophy). Clin J Pain 1997; 13: 50-59.

135 Bruehl S, Lubenow TR, Nath H, Ivankovich O. Validation of thermography in the diagnosis of reflex sympathetic dystrophy. Clin J Pain 1996; 12: 316-325.

136 Wasner G, Schattschneider J, Maier C, Baron R. Skin temperature side differences - a diagnostic tool for CRPS? Pain 2002; 98: 19-26.

137 Kingery WS. A critical review of controlled clinical trials for peripheral neuropathic pain and complex regional pain syndromes. Pain 1997; 73: $123-139$

138 Perez RS, Kwakkel G, Zuurmond WW, de Lange JJ. Treatment of reflex sympathetic dystrophy (CRPS type 1 ): a research synthesis of 21 randomized clinical trials. $J$ Pain Symptom Manage 2001; 21: 511 - 526.

139 Rowbotham MC, Reisner-Keller LA, Fields HL. Both intravenous lidocaine and morphine reduce the pain of postherpetic neuralgia. Neurology 1991; 41: 1024-1028.

140 Watson CP et al. Amitriptyline versus placebo in postherpetic neuralgia. Neurology 1982; 32: 671-673.

141 Max MB. Treatment of post-herpetic neuralgia: antidepressants. Ann Neurol 1994; 35 Suppl: S50-53.

142 Max MB et al. Effects of desipramine, amitriptyline, and fluoxetine on pain in diabetic neuropathy. $N$ Engl $\mathrm{J} \mathrm{Med}$ 1992; 326: 1250 - 1256

143 Dejgard A, Petersen P, Kastrup J. Mexiletine for treatment of chronic painful diabetic neuropathy. Lancet 1988; 1: 9-11.

144 Wallace MS et al. Concentration-effect relationship of intravenous lidocaine on the allodynia of complex regional pain syndrome types I and II. Anesthesiology 2000; 92: $75-83$.

145 Mellick GA, Mellicy LB, Mellick LB. Gabapentin in the management of reflex sympathetic dystrophy. J Pain Symptom Manage 1995; 10: 265 - 266.

146 Davis KD et al. Topical application of clonidine relieves hyperalgesia in patients with sympathetically maintained pain. Pain 1991; 47: 309-317. 
147 Byas-Smith MG, Max MB, Muir J, Kingman A. Transdermal clonidine compared to placebo in painful diabetic neuropathy using a two-stage 'enriched enrollment' design. Pain 1995; 60: $267-274$.

148 Gobelet C, Waldburger M, Meier JL. The effect of adding calcitonin to physical treatment on reflex sympathetic dystrophy. Pain 1992; 48: 171-175.

149 Adami $\mathrm{S}$ et al. Bisphosphonate therapy of reflex sympathetic dystrophy syndrome. Ann Rheum Dis 1997; 56: $201-204$.

150 Varenna $\mathrm{M}$ et al. Intravenous clodronate in the treatment of reflex sympathetic dystrophy syndrome. A randomized, double blind, placebo controlled study. $J$ Rheumatol 2000; 27: $1477-1483$.

151 Schott GD. Interrupting the sympathetic outflow in causalgia and reflex sympathetic dystrophy. Bmj 1998; 316: $792-793$.

152 Verdugo RJ, Ochoa JL. 'Sympathetically maintained pain.' I. Phentolamine block questions the concept. Neurology 1994; 44: 1003 - 1010.

153 Price DD, Long S, Wilsey B, Rafii A. Analysis of peak magnitude and duration of analgesia produced by local anesthetics injected into sympathetic ganglia of complex regional syndrome patients. Clin J Pain 1998; 14: 216 226.

154 Reuben SS, Rosenthal EA, Steinberg RB. Surgery on the affected upper extremity of patients with a history of complex regional pain syndrome: a retrospective study of 100 patients. $J$ Hand Surg [ Am] 2000; 25: $1147-1151$.

155 Blanchard $\mathbf{J}$ et al. Intravenous regional sympatholysis: a double-blind comparison of guanethidine, reserpine, and normal saline. J Pain Symptom Manage 1990; 5: $357-361$

156 Jadad AR, Carroll D, Glynn CJ, McQuay HJ. Intravenous regional sympathetic blockade for pain relief in reflex sympathetic dystrophy: a systematic review and a randomized, double-blind crossover study. J Pain Symptom Manage 1995; 10: 13-20.

157 Ramamurthy S, Hoffman J. Intravenous regional guanethidine in the treatment of reflex sympathetic dystrophy/causalgia: a randomized, double-blind study. Guanethidine Study Group. Anesth Analg 1995; 81: $718-723$.

158 Kumar K, Nath RK, Toth C. Spinal cord stimulation is effective in the management of reflex sympathetic dystrophy. Neurosurgery 1997; 40: 503-508; discussion $508-509$.
159 Kemler MA et al. Spinal cord stimulation in patients with chronic reflex sympathetic dystrophy. $N$ Engl $J$ Med 2000; 343: 618-624.

160 Kemler MA, Barendse GA, van Kleef M, Egbrink MG. Pain relief in complex regional pain syndrome due to spinal cord stimulation does not depend on vasodilation. Anesthesiology 2000; 92: $1653-1660$.

161 Kemler MA et al. Impact of spinal cord stimulation on sensory characteristics in complex regional pain syndrome type I: a randomized trial. Anesthesiology 2001; 95: $72-80$.

162 Hassenbusch SJ et al. Long-term results of peripheral nerve stimulation for reflex sympathetic dystrophy. $J$ Neurosurg 1996; 84: 415 - 423.

163 Rauck RL et al. Epidural clonidine treatment for refractory reflex sympathetic dystrophy. Anesthesiology 1993; 79: $1163-1169$.

164 Takahashi $\mathrm{H}$ et al. The NMDA-receptor antagonist ketamine abolishes neuropathic pain after epidural administration in a clinical case. Pain 1998; 75: $391-$ 394.

165 van Hilten BJ et al. Intrathecal baclofen for the treatment of dystonia in patients with reflex sympathetic dystrophy. N Engl J Med 2000; 343: 625-630.

166 Lee BH et al. Physical therapy and cognitive-behavioral treatment for complex regional pain syndromes. $J$ Pediatr 2002; 141: $135-140$.

167 Sherry DD et al. Short- and long-term outcomes of children with complex regional pain syndrome type I treated with exercise therapy. Clin J Pain 1999; 15: 218 223.

168 Oerlemans HM, Oostendorp RA, de Boo T, Goris RJ Pain and reduced mobility in complex regional pain syndrome I: outcome of a prospective randomised controlled clinical trial of adjuvant physical therapy versus occupational therapy. Pain 1999; 83: 77-83.

169 Baron R, Levine JD, Fields HL. Causalgia and reflex sympathetic dystrophy: does the sympathetic nervous system contribute to the pain?. Muscle Nerve 1999; 22: $678-695$.

170 Baron R, Binder A, Ullrich W, Maier C. Komplexe regionale Schmerzsyndrome. Nervenarzt 2002; 73: $305-$ 320 . 